\title{
Aspectos da avaliação técnico-econômica de circuitos de flotação
}

\author{
Aspects of technical-economic appraisal for flotation circuits
}

\section{Robert Cruzoaldo Maria}

Engenheiro de Produção Mestrado em Engenharia Mineral DEMIN/UFOP

E-mail: rcmaria@gmail.com

\section{José Aurélio Medeiros da}

\section{Luz}

Universidade Federal de Ouro Preto Escola de Minas - Departamento de Engenharia de Minas - DEMIN/UFOP E-mail: jaurelio@demin.ufop.br

\section{Resumo}

A flotação é um dos mais importantes e mais utilizados processos de separação de minerais. Para se promover a otimização completa de um circuito de flotação, para o tratamento de um determinado minério, devem-se considerar suas características técnicas e econômicas. Desta forma, o presente trabalho teve, como objetivo, desenvolver um aplicativo como forma de subsidiar as empresas no que diz respeito ao cálculo da vida útil econômica dos equipamentos de flotação. Para tanto, desenvolveram-se equações para estimar o custo de capital e o custo de operação e manutenção desses equipamentos e aplicou-se o método do custo anual uniforme equivalente (CAUE), para a determinação do momento oportuno de se substituírem tais equipamentos.

Palavras-chave: Equipamentos de flotação; vida útil econômica; CAUE.

\begin{abstract}
Flotation is one of the most important and used processes for minerals separation. It is imperative to take in account economic and technical features to promote the optimization of a flotation circuit. Thus, this study has aimed to develop a computer system in order to meet the mining companies' needs for the calculation of the economic life of flotation equipment. For this, an equation set was developed to estimate the capital cost, and the operation and maintenance costs of the equipment, applying the method of equivalent uniform annual cost (EUAC) for determining the appropriate time to replace such equipment.
\end{abstract}

Keywords: Flotation machine; economic life; EUAC.

\section{Introdução}

A indústria mineral, inserida em um mercado globalizado, necessita, cada vez mais, operar com o máximo desempenho econômico, com produtos de alta qualidade e, ao mesmo tempo, de promover redução de custos para se tornar mais competitiva.

Nesse sentido, o desenvolvimento da indústria mundial nas últimas décadas não teria sido possível sem o uso intenso do processo de flotação, principalmente 
devido à redução das reservas de alto teor e ao aumento da demanda mundial por metais e por outros bens minerais. Dessa forma, os processos de concentração ganharam aceitação geral pelas empresas produtoras.

Segundo Oliveira e Aquino (2005), os processos físicos tradicionais, gravíticos, magnéticos e eletrostáticos, em grande parte baseados nas propriedades naturais dos minerais, não teriam possibilitado a escala de produção necessária dos metais básicos - cobre, chumbo, zinco e níquel - a partir dos de minérios complexos, tanto no que tange às assembleias minerais, quanto aos aspectos de fabricação (como granulação e textura) das mesmas. Também não teria sido possível a produção atual dos metais nobres, nem a produção do fosfato necessário ao desenvolvimento da agricultura. Até mesmo grande parte da produção mundial de minério de ferro, necessário à produção de aço nos níveis de consumo atual, só se tornou possível nas últimas décadas com a utilização, em larga escala, do processo de flotação.

Naturalmente, como registram Abu-Ali e Sabour (2002), a otimização das plantas de mineração não pode ser baseada somente em considerações técnicas. Ao se planejar um circuito de flotação, para o tratamento de um determinado minério, a recuperação mineral, o volume e o número de células no circuito devem ser otimizados com base em considerações técnicas e econômicas.

Diante da importância da flotação, torna-se necessário fazer uma análise da vida econômica dos equipamentos envolvidos nesse processo. Para as empresas serem competitivas, é necessário que elas estejam atentas às inovações tecnológicas e gerenciais. No campo da economia, isso passa por métodos de análise de alternativas de investimentos, objeto de estudo e discussão desse trabalho. A compreensão e a correta aplicação desses métodos são, hoje, universalmente vistas como indispensáveis para melhor alocação dos escassos recursos disponíveis (Halbe \& Smolik, 2003).

Desse modo, desenvolve-se o presente trabalho como forma de subsidiar as empresas, no que diz respeito ao cálculo da vida útil econômica dos equipamentos de flotação.

\section{Materiais e métodos}

A linguagem de programação escolhida para o desenvolvimento do aplicativo foi o $C++$, por se mostrar eficiente quanto aos recursos necessários à realização e apresentação dos cálculos referentes ao custo anual equivalente de operação e manutenção, ao custo anual equivalente de capital e à determinação da vida útil econômica do equipamento. Ressalta-se que foram utilizados o framework Qt e o banco de dados SQLite, todos pertencentes a um grupo de programas denominados software livres, os quais, por definição, podem ser usados, copiados, estudados e redistribuídos sem restrição.

Essa pesquisa utilizou, como base, a metodologia proposta por Abu-Ali e Sabour (2002) para as estimativas de custos, com alguns ajustes que se fizeram necessários. A equação para estimativa de custo de investimento para células de flotação foi obtida por regressão não linear de dados de Mular e Parkinson (1972), atualizados em termos de inflação e mudanças de preço por mudanças estruturais (tecnológicas e trabalhistas) no setor de equipamentos de mineração utilizando-se o índice setorial M\&S Mining and Milling Index.

\section{Fundamentação conceitual}

Primeiramente a questão de otimização econômica surge, em dado empreendimento mineiro, já na fase de desenvolvimento do processo de um empreendimento hipotético de beneficiamento por flotação. Com o intuito de avaliar o desempenho da flotação, considerando-se as implicações que o teor do concentrado e a recuperação do mineral-minério terão sobre a rentabilidade, pode-se adotar, por exemplo, uma função matemática (aqui dita benefício líquido unitário ou específico e se refere a uma tonelada alimentada), a seguir explicitada segundo adoção de Luz (1996).

Sabe-se que $a$, $c$ e $r$ são os teores de mineral-minério, respectivamente, da alimentação e dos produtos, sendo que o concentrado e o rejeito representam as vazões mássicas e estas são igual a: $A, P_{c}$ e $P_{r}$. A recuperação em massa $\left(R_{m}\right)$, isto é, a vazão de sólidos, que se reporta ao concentrado, é dada por:

$R_{m}=P_{c} / A=\frac{(a-r)}{(c-r)}$

A recuperação metalúrgica (sic), portanto, é dada por:

$R=c \times P_{c} /(a . A)=\frac{c \times(a-r)}{a \times(c-r)}$

A receita unitária, resultante da venda do componente valioso contido no concentrado, obtido a partir de 1 tonelada de alimentação será dada por:

$$
\begin{aligned}
& r_{\$}=\frac{a \times A \times R \times p_{\$}}{A}=a \times R \times p_{\$} \\
& r_{\$}=\frac{a \times c \times(a-r)}{a \times(c-r)} \times p_{\$}=\frac{c \times(a-r)}{(c-r)} \times p_{\$}
\end{aligned}
$$

Onde $p_{\$}$ é o preço do componente útil (mineral-minério). Por outro lado, a limpeza total do concentrado em novo estágio do processo acarretaria despesa unitária extra. Considerando a recuperação total dessa operação suplementar de enriquecimento de concentrado igual a 100 \% (já que estaria aí embutido o reciclo do rejeito da limpeza), tal despesa extra (em reais por tonelada) é dada por:

$$
d_{\S}=\frac{P_{c}}{A}(1-c) \times c_{\mathrm{S}}=\frac{(a-r)(1-c)}{(c-r)} \times c_{\S}
$$


Onde $c_{\$}$ é o custo por tonelada de ganga do concentrado do beneficiamento suplementar. O benefício líquido referido à tonelagem de alimentação será portanto:

$b_{S}=r_{\$}-d_{\$}=\frac{c \times(a-r) \times p_{\$}-(a-r)(1-c) \times c_{S}}{(c-r)}$

Embora essa expressão tenha embutidas premissas simplificadoras, admite-se que ela permita medir o desempenho técnico-econômico com grau de realismo suficiente para possibilitar conclusões válidas em âmbito comparativo. Para facilitar a seleção da melhor rota, entre algumas estudadas na fase de desenvolvimento de processo, pode-se usar o valor do benefício normalizado entre 0 e $100 \%$; isto é, para o valor máximo global da campanha, deve-se atribuir valor de $100 \%$ (Luz, 1996).

Uma vez desenvolvido o processo, surge a necessidade de estimar o porte ótimo dos circuitos. A seguir, apresentase o formalismo matemático utilizado para a realização das estimativas de custos, que servem como base para o cálculo da vida útil econômica dos equipamentos de flotação. Para descrição dos aspectos cinéticos do processo de flotação, é usual a adoção de modelo de primeira ordem.

Em processo de primeira ordem, conduzido em batelada, onde a concentração de um dos reagentes (bolhas) permanece invariável durante o processo e há depleção do outro reagente (partículas hidrofóbicas), com taxa de depleção proporcional à concentração residual em dado instante, a cinética pode ser descrita, classicamente, pela expressão (Yianatos, 2005; King, 2001; Klimpel, 1980):

$R=\{1-\exp [-k \times t]\}$

Onde $R$ é a recuperação metalúrgica e $k$ é o parâmetro cinético de flotação. Entretanto essa equação pode apresentar problema de aderência estatística, o qual pode se contornar com algumas modificações (aliás, comuns em sistemas de flotação). A equação clássica foi, primeiramente, aventada por García-Zuñiga em 1935 (Yianatos, 2005) e estabelece que a taxa de flotação de uma espécie, no instante $t$, é proporcional ao montante daquela espécie remanescente na célula, naquele instante.

O primeiro aspecto peculiar, no sistema em estudo, é que a flotação pode demandar um tempo inicial mínimo de aeração, dito tempo de indução $\left(t_{i n}\right)$, antes do qual o percentual recuperado $(R)$ é desprezível. Sob o aspecto puramente de aderência matemática das curvas de regressão, sem considerações heurísticas, esse tipo de fenômeno permite que a equação de cinética de flotação possa ser mais bem descrita por equações do tipo Rosin-Rammler (Weibull) do que pela equação de primeira ordem (tendo o valor do tempo $t$ como a abscissa). Entretanto, uma mudança de coordenadas $\tau_{\mathrm{c}}$ (tempo corrigido), por translação, pode resolver essa desvantagem. Assim, usando-se a análise de regressão não linear, é possível se determinar o tempo de indução.
A segunda modificação comumente vantajosa da equação cinética é o estabelecimento de um patamar máximo de recuperação abaixo dos $100 \%(\mathrm{R} \leq 100)$. Isto significa que uma parcela da espécie mineral nunca flotará por mais tempo em que a operação persista. Exemplo de fenômeno que pode contribuir (no todo ou parcialmente), para esse efeito, e a existência de grânulos mistos com ganga majoritária na superfície exposta, ou o aparecimento de partículas acima do chamado tamanho máximo de flotação. Além disso, pode haver, também, influência da fração de cobertura superficial insuficiente das moléculas do coletor/reforçador, dando como resultado um grau de hidrofobicidade insuficiente para compensar a resultante arquimediana (a qual é função da densidade e do tamanho da partícula). Assim, para o caso de avaliação de cada uma das espécies mineralógicas presentes, a recuperação acumulativa $\left(R_{i}\right)$ da espécie $i$ para cinética de $1^{\mathrm{a}}$ ordem (sem tempo de indução) é dada por (Luz, 1996):

$$
R_{i}=R[i, t]=R_{\infty i} \times\left\{1-\exp \left[-\left(k_{i} \times t\right)\right]\right\}=R_{\infty i} \times\left[1-e^{-\left(k_{i} \times t\right)}\right]
$$

Deve-se notar que modelo alternativo de cinética, que não é infrequente na literatura, é o chamado modelo retangular de Klimpel. Para o caso de avaliação das cinéticas de cada uma das espécies mineralógicas presentes, a recuperação acumulativa da espécie i para cinética retangular (Yianatos, 2005; King, 2001; Klimpel, 1980) é dada por:

$R_{i}=R[i, t]=R_{\infty i} \times\left\{1-\left(\frac{1}{k_{i} \times t}\right) \times\left[1-e^{-\left(k_{i} \times t\right)}\right]\right\}$

Para os propósitos desse trabalho, adotar-se-á a cinética de primeira ordem com o valor típico de tempo de indução nulo. Assim, mudando-se as condições da Equação 8, de regime em batelada, para regime contínuo, com regime de misturador ideal em cada cuba ou célula, estando N células em série (banco), tem-se para a recuperação no conjunto:

$R_{i}=R[i, t]=R_{\infty i} \times\left[1-\frac{1}{\left(1+k_{i} \times \tau\right)^{N}}\right]$

Onde $\tau$ é o tempo médio de residência em cada célula. Explicitando-se esse tempo médio necessário para uma recuperação especificada, resulta, em um banco de células mecânicas em série, em segundos:

$\tau=\frac{\sqrt[N]{\left[\frac{R_{\infty}}{R_{\infty}-R}\right]}-1}{k}$

Onde $N$ é o número de células de flotação em série, $R_{\infty}$ é a recuperação máxima teórica, $R$ é a recuperação metalúrgica especificada (ou historicamente praticada) e $k$ é o parâmetro cinético de flotação da espécie de interesse, com dimensão em s$^{-1}$. Naturalmente, para a obtenção de um tempo médio de residência, deve-se estipular o volume dos reatores (células), o que é função das vazões volumétricas de trabalho. 
A vazão mássica da polpa (em $\mathrm{kg} / \mathrm{s}), Q_{a}$, na alimentação do circuito é dada por:

$Q_{a=} \frac{Q_{s a}}{c_{m a}}$

Onde $Q_{s a}$ é a vazão mássica de sólidos (em kg/s) e $c_{m a}$ é a concentração mássica de sólidos no fluxo.

Por seu turno, a vazão volumétrica de polpa na alimentação, $Q_{v g}$, é dada por:

$Q_{v a}=\frac{Q_{a}}{\rho_{a}}$

Onde a massa específica da polpa (não aerada), $\rho_{a}$, é calculável por:

$$
\rho_{a}=\frac{1}{\frac{c_{m a}}{\rho_{s}}+\frac{\left(1-c_{m a}\right)}{\rho_{f}}}
$$

Onde $\rho_{s}$ é a massa específica do sólido e $\rho_{f}$ é a massa específica do fluido, ambas em $\mathrm{kg} / \mathrm{m}^{3}$.

Nas células de flotação, a vazão volumétrica efetiva deve considerar a fração de espaço preenchido pelo ar dinamicamente apreendido na polpa, referida, usualmente, pelo termo inglês: hold up. A vazão volumétrica da polpa aerada é dada por:

$$
Q_{\text {Var }}=\frac{Q_{v a}}{1-\phi}
$$

Onde $\phi$ é a fração volumétrica do gás (hold up) na polpa aerada.

O volume da polpa, na célula aerada (expressa em m³), será, portanto, dado por:

$$
V_{\text {paerada }}=Q_{\text {Vaer }} \times \tau
$$

$\mathrm{O}$ volume geométrico efetivo da célula deve levar em conta o espaço ocupado por dispositivos acessórios (como rotor, etc.) e o espaço ocupado pela camada de espuma no reator. O volume geométrico da célula pode ser dado por:

$$
V_{\text {Cel }}=\frac{V_{\text {Paerada }}}{\left(1-f_{\text {espuma }}\right) \times\left(1-f_{\text {acessórios }}\right)}
$$

Onde $f_{\text {espuma }}$ é a fração de nível de espuma (borda livre dividida pela altura da cuba) e $f_{\text {acessórios }}$ é a fração de acessórios presentes na célula.

A estimativa do custo de capital $(C c)$ foi desenvolvida pelos autores tendo como base a equação proposta por Mular e Parkinson (1972), cujas constantes foram atualizadas para os dias atuais através da correção do índice $M \& S$, o mesmo utilizado pelos autores supracitados, e, considerando que o custo de aquisição de um equipamento representa cerca de $38 \%$ do custo total do investimento (expresso em reais), gera-se a equação apresentada a seguir:

$C c=7644,8 \times N \times e^{0,84767 \times V_{c e l}^{0,42249}} \times C D$

Onde $N$ é o número de células de flotação em série, $V_{c e l}$ é o volume geométrico da célula e $C D$ é a cotação do dólar em reais. Esta equação apresentou uma aderência de 99,83\% à nuvem de dados regressionais de Mular e Parkinson (1972).

Já os custos de manutenção e operação $(C M)$ foram estimados conforme a Equação 19, apresentada por Abu-Ali e Sabour (2002).

$C M=\frac{N[24 \times \text { Custo.da. Energia } \times n \times 2,4] \times V_{C e l}{ }^{(0,96)}}{0,4}$

Onde $N$ é o número de células de flotação em série, $n$ é o número de dias trabalhados no ano e $V_{c e l}$ é o volume geométrico da célula.

De posse desses dados oriundos das estimativas de custos, aplica-se o método do custo anual uniforme equivalente (CAUE) para cada período. Esse processo deverá ser repetido até que o CAUE do período subsequente seja superior ao CAUE do período precedente. Quando esse fato ocorrer, calcula-se a vida útil econômica desse equipamento, podendo se usar (caso seja necessária maior precisão temporal) algoritmo convencional de interpolação (como, por exemplo, a muito utilizada regressão polinomial de Lagrange).

\section{Resultados e discussão}

O aplicativo foi desenvolvido para estimar a vida útil econômica de equipamentos de flotação. Para tanto, é necessário o desenvolvimento das seguintes etapas: cadastramento das informações gerais, dos dados técnicos e dos dados econômicos. A partir daí, o programa faz as estimativas dos custos de capital e dos custos de manutenção e operação, efetua o cálculo do CAUE e exibe os resultados obtidos.

Inicialmente são registradas informações relativas à identificação do equipamento, tais como o tipo de equipamento, a marca, o modelo e a localização do mesmo. Além disso, o software possibilita ao usuário inserir algumas observações que julgar pertinente.

Após o preenchimento das informações que identificarão o equipamento, são inseridos os dados técnicos referentes ao sistema de flotação, quais sejam: parâmetro cinético de flotação, recuperação metalúrgica, recuperação mássica teórica, número de células de flotação em série, vazão mássica de sólidos, massa específica do sólido, massa específica do fluido, concentração volumétrica do gás (hold up), fração de nível de espuma, fração de acessórios e concentração mássica. 
Na sequência, será exibida a tela de entrada de dados econômicos necessários para a realização dos cálculos, os quais são apresentados a seguir:

- Taxa mínima de atratividade: é uma taxa que representa o mínimo que um investidor se propõe a ganhar quando faz um investimento.

- Taxa anual de crescimento dos custos: é a taxa na qual o custo de operação e manutenção cresce com o passar do tempo.

- Valor residual: refere-se ao valor do equipamento no último ano do período de análise. Há duas opções: a taxa anual de depreciação, caso o equipamento vá perdendo o seu valor de forma gradativa ao longo do tempo, ou o valor de sucata, caso esse equipamento não possua mercado secundário.

- Vida útil do empreendimento (usina) para que esta seja comparada com a vida útil econômica do equipamento.

- Custo da energia: corresponde ao valor gasto pela empresa com o consumo de energia.

- Número de dias trabalhados no ano.

- Cotação do dólar: é referente ao valor do dólar, em reais, na época analisada.

De posse dos dados de entrada, avança-se para o cálculo do custo anual uniforme equivalente, que servirá como critério para determinação da vida útil econômica do equipamento.

Com base no cálculo do CAUE e na comparação da vida útil econômica do equipamento com a vida útil da mina, apresenta-se uma tabela contendo a evolução do custo anual equivalente de capital, do custo anual equivalente de operação e manutenção e do custo anual uniforme equivalente propriamente dito, período a período, até se atingir a vida útil econômica do equipamento, fato caracterizado quando se alcança o ponto de menor valor do CAUE.
O período (ano) em que esse fenômeno ocorrer é adotado como sendo a vida útil econômica do bem. Assim, compara-se esse valor com a vida útil da mina. Isto porque uma das condições básicas para se efetuar a substituição desse equipamento é que sua vida útil econômica não seja maior que a vida útil da mina. Caso contrário, o investimento não seria recuperado em tempo hábil.

A fim de se ilustrar a aplicação do software desenvolvido nesse trabalho, apresenta-se um projeto hipotético de cálculo da vida útil econômica de um equipamento de flotação, analisando a viabilidade de promover a sua substituição. Os dados de entrada serão apresentados a seguir.

\section{Informações gerais}

• Equipamento: Célula mecânica de flotação

- Marca: W

- Modelo: Open Flow

- Localização: Mina X

\section{Dados técnicos}

• $k$ : parâmetro cinético de flotação $=0,015 \mathrm{~s}^{-1}$ (deve-se ressaltar que essa alta taxa específica de flotação acarreta o baixo tempo de residência calculado adiante).

- $R$ : recuperação metalúrgica $=92 \%$.

- $R$ : recuperação mássica teórica $=96 \%$.

- $N$ : número de células de flotação em série $=8$.

- Q : vazão mássica de sólidos $=25 \mathrm{~kg} / \mathrm{s}$.

- $\rho_{s}$ : massa específica do sólido $=3500 \mathrm{~kg} / \mathrm{m}^{3}$.

- $\rho_{f}$ : massa específica do fluido $=1000 \mathrm{~kg} / \mathrm{m}^{3}$.

- $\phi$ : concentração volumétrica do gás (hold up) =0,12

- $f_{\text {espuma }}$ : fração de nível de espuma $=0,03$.

- $f_{\text {acessórios }}$ : fração de acessórios $=0,05$.

- $C_{m a}$ : concentração mássica $=0,40$.

\section{Dados econômicos}

- Taxa mínima de atratividade $=12 \%$.

- Taxa anual de crescimento dos custos $=15 \%$.

- Valor residual: será considerada uma taxa anual de depreciação de $10 \%$.

- Vida útil da mina = 20 anos.

- Custo da energia $=\mathrm{R} \$ 0,02 / \mathrm{kW}-\mathrm{h}$.

- Número de dias trabalhados no ano = 365 .

- Cotação do dólar: R\$1,90.

Após a inserção desses dados no aplicativo, é efetuado o cálculo da vida útil do equipamento, que será exibido no relatório gerado pelo sistema em formato pdf, ilustrado no Quadro 1.

Cabe destacar que, para o exemplo hipotético, a vida útil econômica da célula é de 9 anos (valor conservadoramente baixo) e, como a vida útil da usina é de 20 anos, torna-se viável a substituição da célula ao término desse período. 
Quadro 1 - Relatório gerado pelo aplicativo com dados de processo típicos.

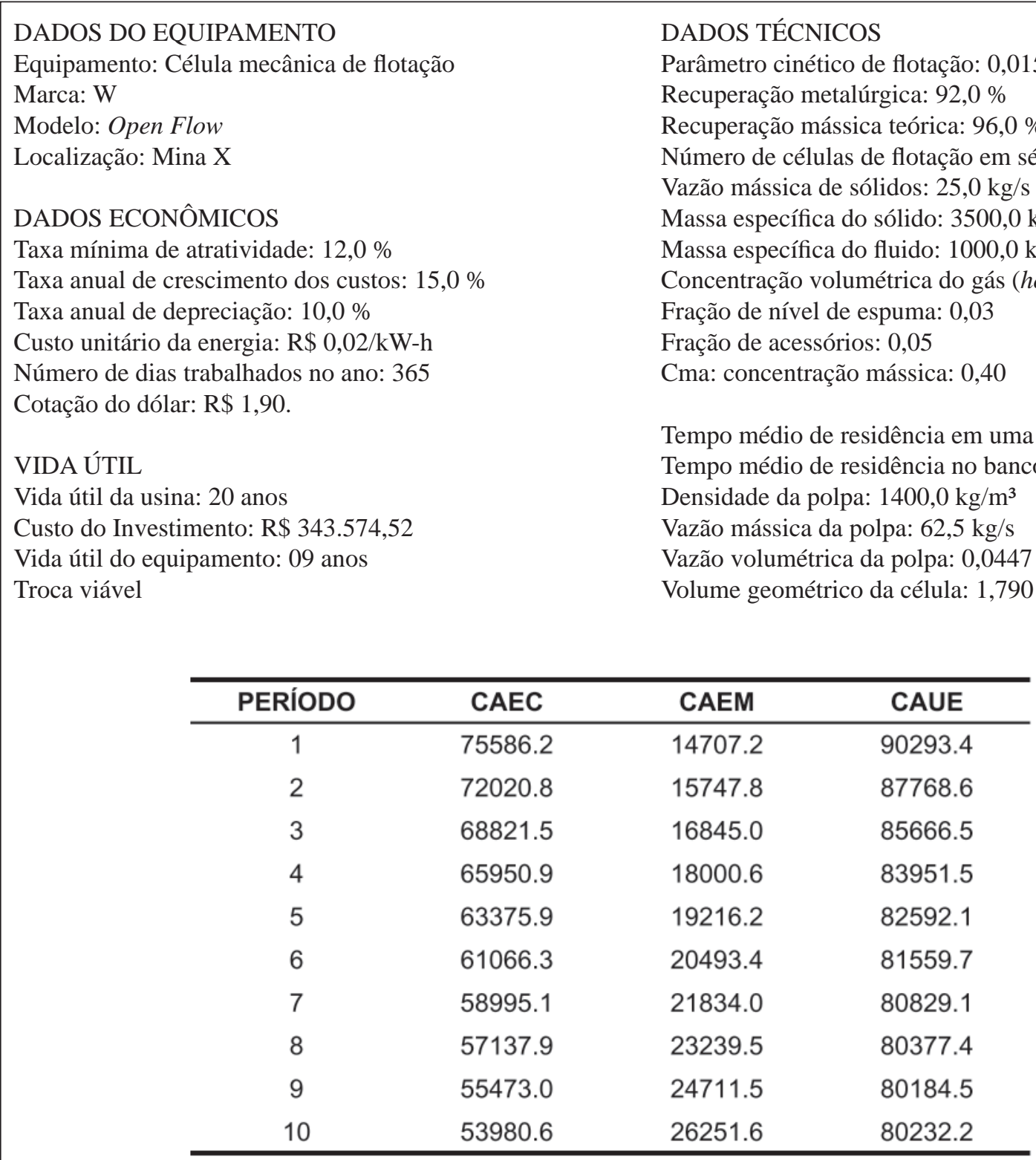

Na parte inferior do Quadro 1, é exibida a progressão do custo anual equivalente de capital (CAEC), do custo anual equivalente de manutenção e operação (CAEM) e do custo anual uniforme equivalente (CAUE), para cada período, até que o CAUE do período subsequente superasse o valor do CAUE do período precedente. Alguns parâmetros técnicos calculados também são exibidos, como o tempo médio de residência na célula (32,5 s), o tempo médio de residência no banco (4,33 minutos), a massa específica da polpa (1400 kg/m³), a vazão mássica da polpa (62,5 kg/s), a vazão volumétrica da polpa $\left(0,0447 \mathrm{~m}^{3} / \mathrm{s}\right)$ e o volume geométrico da célula $\left(1,790 \mathrm{~m}^{3}\right)$.

\section{Conclusão}

O propósito dessa pesquisa foi desenvolver uma ferramenta de análise de permutação de ativos fixos capaz de servir como suporte para os gestores das em- presas tomarem decisões no que tange à substituição dos equipamentos de flotação através do cálculo de sua vida útil econômica. O módulo aqui apresentado restringiu-se a banco de flotação mecânica convencional.

O estudo de viabilidade da troca de equipamentos de flotação é de toda conveniência para qualquer organização, uma vez que tal estudo está diretamente relacionado com o desempenho técnico e com os custos de produção e, consequen- 
temente, com o valor do produto final. A análise apresentada, nesse trabalho, demonstrou-se ser bastante segura, pois se baseia em uma ampla análise de questões técnicas, econômicas, etc., as quais servem de suporte para a tomada de decisões por parte dos interessados.

Dessa maneira, o software desenvolvido apresenta os recursos necessários para que os analistas possam, através de sua utilização, determinar o momento ótimo da substituição, bem como proceder às variações percentuais dos principais indicadores econômicos de forma a obterem diferentes cenários para operarem a substituição. As partes-chaves do programa-fonte estão disponíveis em Maria (2009).

Os resultados gerados pelo programa são obtidos com baixo esforço computacional e fundamentados nas técnicas tradicionais já consagradas no cálculo da vida útil econômica.

Outro aspecto importante é o fato de a interface do programa ser de fácil utilização, sendo bastante similar aos aplicativos encontrados no mercado. Também são gerados relatórios detalhados para o acompanhamento das informações cadastradas e geradas pelo sistema.

\section{Referências bibliográficas}

ABU-ALI, M. H., SABOUR, S. A. Optimizing the design of flotation circuits an economic approach. Minerals Engineering, November/2002. 6p.

HALBE, D., SMOLIK, T.J. Process Operating Costs with Applications in Mine Planning and Risk Analysis. In: Northwest Mining Association Annual Meeting. Spokane, WA, December/ 2003. Spocane: NMA, 2003. 23p.

KING, R. P. Modeling \& simulation of mineral processing systems. Boston: ButterworthHeinemann, 2001. 403 p.

KLIMPEL, R. R. Chapter 45: selection of chemical reagens for flotation. In: MULAR, A. \& BHAPPU, R. B. (Ed.). Mineral Processing Plant Design (2th ed.). New York: SMEAIME, 1980. p. 907-933.

LUZ, J. A. M. da. Flotação aniônica de rejeito itabirítico: estudo de reagentes alternativos e modelamento polifásico do processo. Belo Horizonte: EEUFMG, 1996. 574 p. (Tese de Doutorado).

MARIA, R. C. Otimização técnico-econômica de circuitos de flotação. Ouro Preto: UFOP, 2009. 96 p. (Dissertação de Mestrado).

MULAR, A. L., PARKINSON, E. A. Mineral processing equipment costs and preliminary capital cost estimations. Montreal: Canadian Institute of Mining and Metalurgy. v. 13, 1972. 141p.

OLIVEIRA, M. L. M., AQUINO, J. A. Aspectos relevantes das colunas de flotação. In: ENTMME, 21. Anais... Natal: CETEM, novembro/2005. p. 243-250.

YIANATOS B.J. Flotación de minerales.Valparaíso: Universidad Técnica Frederico Santa María, 2005. 130 p.

Artigo recebido em 15/08/2009 e aprovado em 28/01/2010.

\section{REM - Revista Escola de Minas}

Primeira revista do setor

mínero-metalúrgico a obter certificação ISO 9001:2008

www.rem.com.br

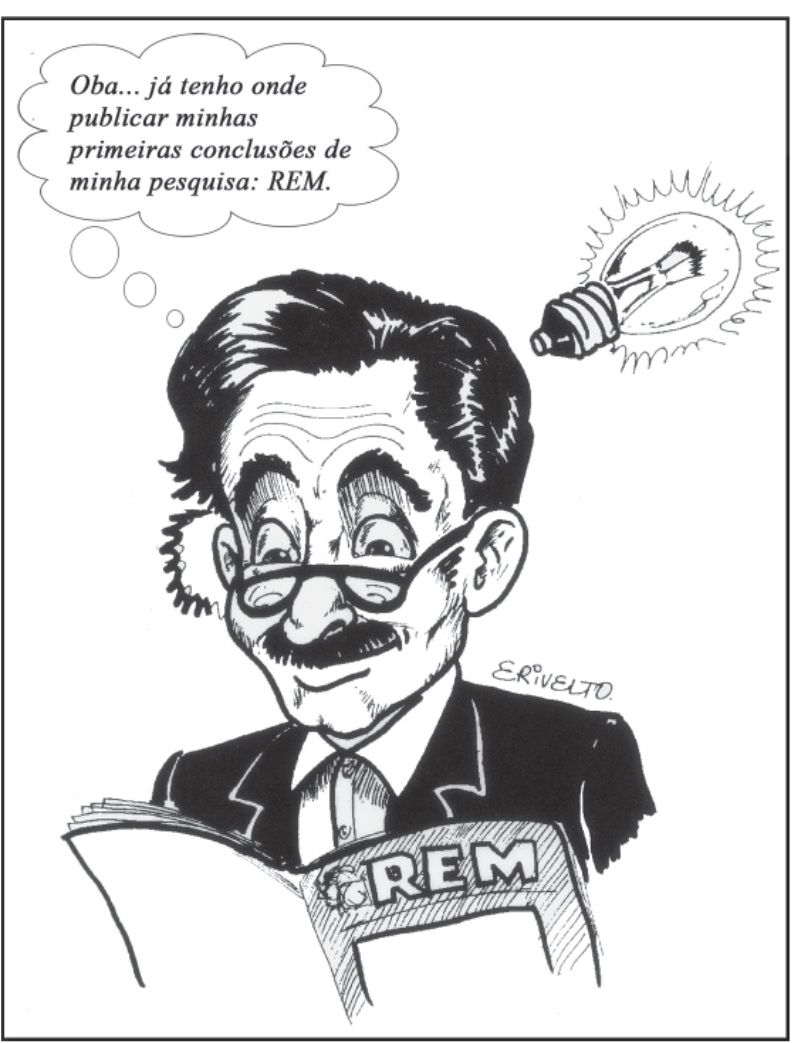

